\title{
Supporting school improvement: the development of a scale for assessing pupils emotional and behavioural development
}

\author{
Michael Grimley*a ${ }^{\mathrm{a}}$, Sue Morris ${ }^{\mathrm{b}}$, Stephen Rayner ${ }^{\mathrm{b}}$ and Richard Riding ${ }^{\mathrm{b}}$ \\ ${ }^{a}$ University of Canterbury, New Zealand; University of Birmingham, UK
}

This paper reports the construction of a teacher rating instrument designed to monitor the social and emotional development of school age children and young people (4-17 years). The instrument was developed by reviewing previously implemented checklists to build an extensive list of behavioural and emotional criteria and through the use of focus groups to establish the views of key stakeholders. The criteria were categorized according to three areas:- conduct, emotion and learning. The initial instrument of 21 items was piloted and amended accordingly. The final trial of the instrument was carried out on a sample of 7285 pupils from a cross-section of UK schools. A principal component factor analysis confirmed the division of the scale into three factors. The instrument was supported by trends showing that the distributions were different for different types of schools and between males and females. The final version of the instrument was amended to include 15 items, five in each category (conduct, emotion, learning), all expressed positively on a six-point scale. The scale is a useful tool for providing a basis for a strategic discourse between staff in planning approaches to the emotional and behavioural development of students in school.

\section{The scope of the project}

\section{Background}

This paper details the development of an instrument designed to monitor pupils emotional and behavioural development in early years and school settings. The work was undertaken for the Qualifications and Curriculum Authority (QCA) in England, with the primary purpose of providing an evidence base to inform the cyclical process of school review and target-setting to support the social and emotional development of groups of pupils (DfEE, 1998).

\footnotetext{
* Corresponding author. School of Education, University of Canterbury, Private Bag 4800, Christchurch, New Zealand. Email: michael.grimley@canterbury.ac.nz
} 
The intention was that the instrument would facilitate school improvement in both Mainstream and Special School settings, across Key Stages 1-4, balancing the focus upon educational attainment which was, by this time, well-established in schools, with data routinely collected and used within rigorous externally accountable cycles of assessment, data analysis, target-setting, and planning for continuous improvement. The aim of the commissioned assessment instrument (hereafter referred to as the Scale ) was to provide a simple framework that could assist educational settings in monitoring and planning provision for the social and emotional development of children and young people, in conjunction with a focus on raising standards of academic attainment.

The intention of the Scale was for use by teachers to monitor the development of all pupils rather than simply to profile pupils whose development gave cause for concern. Consequently, the instrument needed to meet a number of criteria; namely, be simple; capable of being easily understood and used without extensive training or specialized skills in test administration or structured observation; quick to administer, score and analyse; cover a wide age range; be suitable for whole school use; and provide valid and reliable data.

For the emotional and behavioural difficulties (EBD) context in the UK, important issues about assessment are raised by recent legislation (DfEE, 1997), particularly with respect to how target-setting and new forms of assessment may be linked effectively to teaching and learning (DfE, 1993). For an assessment-based curriculum to work, there is a need for a process which not only provides a record of accountability, but also positions evaluation and continuous assessment at the heart of a working pedagogy and school practice (Marjerison \& Rayner, 1999).

It was intended that the Scale should have value in:

- $\quad$ monitoring pupil progress;

- $\quad$ aiding teachers in analysing patterns of strength and weakness, and targeting teaching and other forms of intervention accurately; and

- $\quad$ facilitating the internal formative evaluation of the effectiveness of each school s personal, social and health education and citizenship curricula.

Overall, therefore, it was envisaged that the assessment of emotional and behavioural competence would have value in driving curriculum development, teaching practice and 
school effectiveness, through informing cycles of individual and group development, which are understood to underpin work aimed at school improvement (see Figure 1)

[f/] Figure 1 about here [/f]

In commissioning the development of the Scale, DfES/QCA were mindful that improved emotional adjustment and behaviour will, in the majority of cases, produce better learning, and that this, in turn, is likely to enhance self-perception and self-efficacy. This results in an increase in motivation, which in turn, leads to even better behaviour and academic learning. The components of this cycle of development reflect aspects of emotional growth and process skills (Greenhalgh, 1994). The two critical phases of the Improvement Cycle are behavioural and emotional development (1) and learning (2). If pupils do not engage then they will not learn, but even if they do attend to their studies and the teaching is not effective they still will not learn. Behaviour management and appropriate meaningful programmes of instruction need to be combined together to generate an Improvement Cycle. Additionally, of course, socially skilful behaviour and emotional resilience are accepted in society as valued ends in themselves, regardless of their instrumental value in teaching and learning.

\section{Methodological considerations and implications for study design}

While the present project was targeted on the construction of a rating scale that could be used to monitor emotional and behavioural development, it is important to acknowledge that the Emotional and Behavioural Development Scale should be one element within a more comprehensive assessment and curriculum process in schools. Additionally, the process of assessment and interpretation of data would need to take account of the fact that the assessment process would inevitably be subjective, and that the object of assessment (pupil behaviour and emotional processing skills) is inconsistent, varying considerably across situations, and at different points in time.

Burrell and Morgan (1979) provide an account of social reality based upon bipolar representations of ontology, epistemology, and human nature, and discuss the research 
methodologies that can legitimately be used in the light of the philosophical stance adopted. These bipolar representations are based along a subjectivist-objectivist continuum:

Ontology is concerned with assumptions made about the nature of truth or reality , in relation to the social phenomena that are the subject of analysis. Debate centres upon the extent to which reality is external to, and independent of the individual, or in contrast, resides within the individual - the product of her/his individual cognitive processes. At one end of the continuum are the realist or objectivist beliefs that have characterized traditional scientific research, which assume that objective realities exist; such a perspective would view pupils behavioural traits as stable entities, which, subject to due rigour within the assessment process, would be rated equivalently by different observers, so assuring very high rates of inter-rater reliability. This orientation is contrasted with nominalist, relativist or subjectivist positions, which assume that objects in the world have no meaning or existence independent of the individual who perceives them: reality is socially constructed. Within the subjectivist, or relativist paradigm, judgements about a pupil s emotional and behavioural development would depend as much upon the observer, the contexts in which observations had been collected, the mind-set of the observer, and her relationship with the pupil who is the object of her attention, and the relation of both observer and pupil to the contexts within which the observations are made. Such an interactionist, ecological view allows for the social construction of reality, and the legitimacy of different observers seeing different things and forming different judgements, because of the different positions they hold, which may lead to different perceptions of the same events, and/or to different events occurring within the social contexts which different individuals create.

Epistemology is concerned with the study of knowledge. Cohen et al., (2001) explain how the epistemological approach adopted by a researcher will have a major impact upon how s/he will choose to explore, or uncover relationships between areas of knowledge or social behaviour. On the one hand, a positivist (objectivist) approach would view knowledge as hard : a question of facts to be acquired; on the other hand, an anti-positivist (subjectivist) orientation would view knowledge as inherently value-laden, personal to the individual, and the product of personal experience. As Cohen et al. (2001) suggest, the epistemological approach adopted by a researcher will clearly impact on how s/he might set out to explore and uncover knowledge about human behaviour.

Views about human nature are concerned with the relationship that exists between humans and their environment. As Burrell and Morgan (1979) suggest, an 
objectivist/determinist position views humans as responding in a mechanistic, or even deterministic fashion to situations encountered in the external world. Human beings are regarded as products of the environment. In contrast, a subjective/voluntarist position views human beings as occupying a more dynamic role, characterized by free will, and the capacity to influence or create their environment.

These dimensions are significant in positioning the present study, which adopts an interpretive methodological stance that is concerned with collating the subjective perceptions, experiences and beliefs of members of staff within the specific work settings in which they encounter the children whose social and emotional skills they assess. The development team anticipated that in some schools, pupils would also be invited to use the Scale, to contribute their own self-assessment data, and compare this with teacher perspectives. Sherman and Webb (1988) argue that an interpretive approach to research should be located in a natural setting, acknowledging the place of context in shaping behaviour, and seeking to give those who are the subject of the research opportunities to take an active role in speaking for themselves. The approach seeks discovery of subjective realities, which may form the basis for theory development, in contrast to the role of traditional empiricist research in seeking to verify a pre-existing theory (Guba \& Lincoln, 1989).

This paradigm has major implications for the conceptualisation of the assessment process, and the status of the data collected. Given the essentially subjective nature of teacher assessment of pupil behaviour, and the contextual specificity of the data collected:

- $\quad$ the data cannot be assumed to represent child attributes which are necessarily consistent across situations, or even at different times within the same situation;

- different raters may legitimately form different perceptions of the child because the child behaves differently in the contexts within each observer has viewed the child;

- $\quad$ different raters may have formed different opinions about the child as a result of their own values and perceptual processes.

If the Scale were designed to function as a reliable clinical index for discriminating between pupils, or for collating sensitive diagnostic profiles of children, these factors would represent major shortcomings that would invalidate the instrument.

However, given that the primary focus of the Scale is to promote school improvement, the subjective nature of judgements, and the social constructivist and social interactionist 
processes through which these judgements are formed, add to, rather than detract from the practical utility of the data. Clearly, it is important that the instrument is deemed to be both reliable and valid within the purpose of its use. Firstly, reliability is essential for any instrument and is a pre-requisite of validity (Robson, 2002). However, validity is a condition that can only be met according to the paradigm within which the instrument is set (Cohen et al., 2001). As described above the subjectivist nature of this instrument places the validity firmly on the purpose to which it is used rather than the results of the instrument per se. For example the instrument is valid if it is useful for informing the cycles of individual and group development. In addition, if the instrument is to be used to inform of a pupil s individual progress in the area of emotional and behavioural development then it should also observe other standardized measures of reliability and construct validity. In this instance the validity is confirmed if the cycle of improvement is enhanced with its use.

Within the interpretivist paradigm, soft data such as those that would be derived from completion of the Scale in schools, have value in supporting ecologically-based whole systems thinking. Here, Learning Organization theory, developed from the work of Argyris and Schon (1978), and Senge (1990, 1994, 1999) offers a highly relevant theoretical approach, with its concern with understanding and shaping the organizational structures and cultures which, recursively, shape the capacity of the school as an institution, to learn, and to respond swiftly and intelligently to fast-changing environments, and externally-imposed change. Argyris and Schon (1978) assert that this framework can assist school staff to 'extend their capacity for multiple viewing of organizational phenomena, ... to tolerate and deal with conflict, ... and to learn to model good organizational dialectic' (p. 313). This theoretical approach allows staff to scrutinize data derived from data collection tools, and to question their meaning. If two teachers have very different perceptions of the same pupils or group, how are these differences to be explained? Is it the case that the pupils' behaviour is indeed different, as a result of different curricular or organizational demands, peer group influences, or the teachers own personal style and relationships, for example. Such an interrogative, discursive process in which shared meanings of every-day phenomena are constructed collaboratively by members of the staff team, is a critical element in the school improvement process. Additionally, such critical discourses will, over time, strengthen the consistency of judgements made by members of the staff team, leading to improved levels of internal reliability. 
Clearly, learning organizations are feedback-dependent and data-driven. Angelides and Ainscow (2000) emphasize that the task of making positive changes in organizations via teacher attitudes and actions should begin by collecting evidence. This offers an opportunity for subsequent scrutiny (where different interpretations and implications of the collected evidence can be considered and reviewed by different stakeholders), prior to deeper levels of questioning of the assumptions behind the different interpretations, as a foundation for development of shared mental models, vision and team learning. Overall, therefore, the subjectivist, interpretivist paradigm and the situated, and potentially diverse nature of teachers judgements, may be seen as a strength of the Scale, and integral to the process of school improvement which its use is designed to promote within schools, as learning organizations.

However, the conceptualization of the present study also employs more traditional, positivist epistemological assumptions. We assume that, in schools which have in place many systems to ensure that staff are competent, and that the environment is regulated by consistently implemented policies, there will be more commonalities than differences in the way in which pupils are viewed by different staff members. Therefore, in the design of the Scale, we were keen to design an instrument that would be capable of producing an acceptable level of inter-rater reliability, and where data could be shown to be giving information about pupil characteristics, rather than predominantly capturing highly idiosyncratic judgements of particular raters. Consequently, during the construction of the scale the researchers drew upon instruments that were already in existence and used behavioural and emotional descriptors that would have some shared meaning for teachers in the classroom. With these broad principles in mind, the Project comprised two phases, which are described below. Phase one describes the development of the scale followed by phase two which describes the main piloting of the scale.

\section{Project: phase one}

Procedure.

This phase comprised: 
(1) A review of the literature and materials commonly used to assess emotional and behavioural development.

(2) A postal questionnaire to determine current practice and examples of initiatives from,

(a) Principal Educational psychologists in all English Local Education Authorities (LEAs), and

(b) (b) relevant professional organizations, such as the Association of Workers for Children with Emotional and Behavioural Difficulties (AWCEBD).

(3) An initial version of the behavioural and emotional criteria drafted for use at both primary and secondary levels.

(4) The initial version of the criteria was trialled in a Mainstream secondary school. The use of a Mainstream school was necessary at this stage since in many EBD schools there are more boys than girls, and further it put the emotional and behavioural criteria into a wider context. Where possible, several teachers rated each child in order to assess the degree of inter-rater agreement. A factor analysis of the ratings to each criterion was undertaken to check how they clustered on specific factors, and to indicate redundant criteria or the need for additional items.

(5) A series of focus group meetings of practitioners, (Special School and Mainstream teachers, Special Educational advisors, and Educational Psychologists) met to discuss and comment on the draft criteria, which would then be modified as appropriate.

\section{Results}

Review of assessment of emotional and behavioural development literature

The review was carried out to find publications (books, journal articles and tests) that included checklists or observational criteria that were intended to measure social and emotional development, or identify emotional and behavioural problems in children. Relevant sources were identified. In addition, information from the Questionnaire Survey of LEAs (see following section) was incorporated into this review. 
Four behaviour development checklists of emotional and behavioural development were identified in the literature. The first of these was a behaviour curriculum developed at Trafford Metropolitan Borough Council described above (Bate \& Moss, 1997). In form and scope the Trafford checklist is similar to the second identified instrument; namely, the Walker-McConnell Scale of Social Competence and School Adjustment which is used in the USA and also Australia (Walker \& McConnell, 1995). Unlike the Walker-McConnell instrument, the Trafford instrument is easily capable of being used to create a profile of development for individual pupils.

Thirdly, a profile of primary aged pupils, the Boxall Profile, (Bennathan \& Boxall, 1998) gives a way of assessing the needs of children and their development once intervention has taken place. These scales are limited to the primary age band and describe basic early behaviour patterns. Consequently, they do not reflect either normal development or the range of behaviour problems encountered across the full 4-17-continuum.

Finally, Cumbria LEA had produced a developmental behaviour scale aimed principally at primary school pupils. The scale comprised five levels and ten behaviour categories including independence and organization, self-image and esteem, motivation, reflection/self-control, attention, honesty, co-operation, collaboration, sociability and empathy. The sources identified in this review of assessment instruments together with materials from LEAs, were used to compile an extensive list of behavioural descriptors. The descriptors represented negative aspects of behaviour and were used as a basis for version 1 (see Appendix 1) of the scale (described below).

\section{Findings from the LEA Survey}

The questionnaire was sent to all 134 Principal Educational Psychologist in LEAs in England. Forty-four questionnaires were returned. The amount of information provided ranged from very detailed in the case of eight LEAs to less full for the remaining 36.

From the questionnaires it was evident that LEAs used a wide range of both homeproduced and externally published assessment instruments. On the basis of the information obtained, it was found that the most common systematic approaches to assessing social and emotional development in educational settings relied to a large extent on behavioural checklists. However, some LEAs are moving towards models which place more emphasis on 
the environment, rather than on a deficit model blaming the child (e.g., Birmingham s Frameworks Assessment-Birmingham LEA, 1998).

Nineteen respondents reported that they employed mainly LEA-produced checklists, nine LEAs utilized published materials when undertaking assessments, five used a mixture of published and LEA-produced materials, and the remainder did not specify their policy.

The majority of the checklists appeared to be used for the purpose of identifying/confirming that emotional and behavioural difficulties (EBDs) are exhibited by a particular child, preparing recommended interventions, and often as part of a statementing process.

The instruments/checklists, typically comprised of large number of items, so rendering them very time-consuming for a teacher to administer. A similar constraint also applied to the examples of EBD/classroom management checklists supplied. Very few checklists appeared to be systematically applied with the specific aim of monitoring emotional and behavioural development. Trafford and Cumbria were the exception here. Trafford Metropolitan Borough Council supplied evidence of a comprehensive checklist of emotional and behavioural development (see Bate \& Moss, 1997). Trafford s checklist contains 64 items covering peer relations, self-responsibility/problem solving, emotional control, acceptance of authority, self-worth, classroom conformity and task orientation. Cumbria also provided an extensive checklist for emotional and behavioural development.

\section{Preliminary work on the Emotional and Behavioural Development scale—version 1}

Initial structure of the scale was based on the finding of Riding and Al-Hajji (2001) who used a 21-item checklist and found that a factor analysis showed that the behaviours could be grouped as three areas of behaviour performance-conduct, emotional and learning.

Conduct behaviour has to do with behaviours such as co-operation, lack of physical aggression, respect for property and the belongings of others, freedom from verbal aggression and inappropriate interruption, and regular attendance.

Emotional behaviour is concerned with frequently appearing miserable or content, unhappy or happy, distressed or relaxed, and with respect to anxiety, freedom from unreasonable fear, a lack of unnecessary worry, and a reasonable level of self-confidence. 
Learning behaviour involves activity related to instruction and process skills, for example, a commitment to follow instructions and to complete tasks, making effort to participate in class discussions, concentration and extended attention span, persistence even with more difficult tasks, and an apparent interest in school work.

For the scale to be developed there was the need to group the behaviour descriptors that had been found in the LEA checklists and the tests reviewed in the desk research. Thus, descriptors were sorted using the three general categories. Many of the descriptors of problem behaviours were repeated across different checklists. Some items on the original list were excluded from the checklist, as they were not clearly defined. For example squirmy, stubborn, masculine, etc. As the rating scale was to be administered mainly by teachers items needed to relate to readily observable behaviour which would be exhibited by children and young people in the school setting, reducing subjectivity as far as possible by ensuring that teacher ratings were based upon samples of observed behaviour.

Once items had been sorted, 21 specific behaviour categories were identified under the various headings. From these categories a definitive phrase was constructed to describe the negative behaviour and a number of examples of such behaviours were included to further clarify the nature of the category. Positive statements and examples were then constructed for the items. The two poles of undesirable and desirable behaviours were then joined to give a list of 21 bi-polar dimensions of behaviour (see Appendix 1). A seven point rating scale was selected as this offered a range for development but was not so large as to be unmanageable. The type of rating scale used within the instrument was a seven point graphic scale anchored using the description of negative/undesirable behaviour at point one and positive desirable behaviour at point seven (Kline, 1993). Kline comments that graphic scales such as the one used here are more reliable and easier to use than numerical scales that have a definition at each point. Instructions for use of the scale emphasize that the scale should be interpreted in terms of the amount of improvement needed for the pupil to reach point 7 on the scale and that both severity of behaviour and frequency of behaviour should be taken into account.

\section{Initial piloting of scales—version 1}

Version 1 of the Emotional and Behavioural Development Scale was given a trial at a Mainstream secondary school with 247 Year 9 (13-14yrs) pupils. A total of 12 teachers from 
three subject areas (mathematics, religious education and geography) received instructions and an accompanying teacher questionnaire, which asked them to comment on the clarity and relevance of the items. All pupils were rated by at least one teacher.

A factor analysis of the results generally confirmed the three categories of conduct behaviour, learning behaviour and emotional behaviour. Teacher comment on the scale suggested that it was easy and fairly quick to complete and generally clear.

\section{Focus groups}

A series of seven focus groups were prepared to obtain opinion on the factors relevant to the development of the criteria. These groups involved a total of 56 practitioners and experts from all of the English regions. These included Special and Mainstream school teachers, Special Needs advisors and educational psychologists. The membership of the focus groups was drawn from the names of those responding to the LEA survey, nominations by QCA, and others already known to the research team.

The Focus Groups considered several issues that emerged from this review phase, and these included the following:

(1) Assessment of Emotional and Behaviour Performance.

(a) Which observable states/behaviours should be included in the assessment?

(b) Is it possible to have a scale applicable to both the EBD Special School and Mainstream settings?

(c) How would a balance be achieved between the behaviours that should be included and the need to have a scale that can be completed within a reasonable time?

(d) Who should do the rating? For instance, in secondary schools several members of staff will teach the same pupil, while in primary schools only one teacher may have frequent contact with a pupil.

(e) How can ratings be moderated across schools?

(f) How often should ratings be done?

(g) What type of rating scale should be used? 
(h) Will different scales be needed for pupils of different ages?

(2) Towards a model of emotional and behaviour causation and development.

(a) How is it possible to distinguish between the developmental and nondevelopmental aspects of behaviour?

(b) What are the range of factors affecting emotional and behaviour difficulties, and which of these are open to teacher intervention?

(c) How should gender differences be accommodated?

(3) Target-setting

(a) How should assessments be interpreted in setting targets?

(b) What formative information, or other data, would be likely to help teachers in the interpretation of the assessment?

(c) How can teachers be guided in setting realistic targets?

(d) What remedial help and support can teachers give to pupils to help them to reach the targets?

The focus group discussions highlighted areas considered important in the development of the assessment. These may be summarized as follows.

The assessment criteria. The criteria used to generate the scale items were perceived to be valid, user-friendly, relevant, and the items were shown to be generally successful. Some modifications were identified from the feedback provided by focus groups. Key comments included:

Generally the draft assessment criteria (Version 2) were considered satisfactory in terms of their content but would benefit from the use of positive statements of behaviours within the scale.

The need for elaborations of the criteria descriptions to clarify the content, in the form of a related guidance booklet for teachers, was suggested.

Some minor alterations to particular items were proposed. 
The general feeling was that a seven point defined scale would be possible - fewer levels would be too restrictive and more would be difficult for teachers to complete.

With respect to the frequency of assessment, annual profiling was thought to be appropriate for most pupils.

Moderation was considered to be possible within schools, but difficult between schools. Many emphasized the problems of the notion of a developmental scale because of the nonlinear nature of behavioural and emotional progress.

There was the general feeling that the criteria could be used over a wide age range because teachers would adjust expectation to their own context.

Context. The importance of context was high-lighted and included:

There was a strong feeling of the importance of considering behaviour within the whole context of the factors likely to affect behaviour.

Factors were seen as including the home, the neighbourhood, peer pressures, the school, and within child factors (gender, intelligence, cognitive style, etc.).

Target-setting. The utility of this assessment was perceived by focus groups to be firmly linked in a wider framework of assessment and target-setting. Key comments included:

It was felt that the elaboration of the criteria would allow behaviours to be broken down into small stepping stones that could be used to form targets for pupils and teachers to work towards by means of social training and the development of coping strategies.

Some groups were concerned to see individual and institutional target-setting integrated.

Application. Greatest criticism or reservation about the rating scale and its development lay with concern about purpose and utility. Much of this concern was expressed in notions of accountability and a political agenda, reflecting anxiety about potential measures of comparison being used between schools as part of the naming and shaming culture of inter- 
school performance, league tables and value for money being driven by Ofsted school inspections and central government. Key comments included:

Several people stressed the need for clear training for teachers in the use of assessments and target-setting.

Many raised questions about the long-term purpose of this development and a few expressed strong apprehension about its eventual intent and use. Apprehensions were strongest from staff in EBD schools.

\section{Scale refinement-towards Version 2}

On the basis of the results of the initial trial and the focus group meetings the Emotional and Behavioural Development criteria was further refined by:

- $\quad$ expressing all the items positively and modifying the content of some items;

- the development of extended descriptions of the behaviours;

- the use of a six point scale; and

- grouping the items into sections to help teachers to focus attention on target-setting. Version 2 of the rating scale, and the extended description of the behaviours, is given in Appendix 2.

\section{Project: phase two}

\section{Sample}

The participation of schools was on a volunteer basis, but covered all the English regions with a rural/urban mix. Over 13,000 rating scales and nearly 900 teacher packs were sent to a total of 60 EBD schools, 10 Severe Learning Difficulties/Moderate Learning Difficulties (SLD/MLD) schools and 75 Mainstream schools.

Since participation in the trial was voluntary, schools were free to select pupils, subjects and teachers as was convenient to them. The number of pupils rated by a school ranged from around 20 to several hundred. Responses were received from 99 schools and scored appropriately. The schools were grouped as EBD Schools (including EBD day and/or 
boarding, both single and mixed sex, and pupil referral units), SLD/MLD Schools, and Mainstream Schools. The data available are shown in Table 1.

[t/] Table 1 about here $[/ t]$

\section{Instrument/materials}

The rating scale used a six point scale which was scored from 0 to 5 , with 5 being the best behaviour, ( Not at all , 0; Rarely , 1; Sometimes , 2; Fairly often , 3; Often , 4; Always , 5). This gave a score of 35 for each behaviour group and a total maximum score of 105 for the whole scale.

The rating scale was accompanied by an elaborated description of each behaviour with some specific examples of that behaviour and was intended to give raters a better understanding of the behaviours described in the rating scale (for example, see Appendix 3(b)).

\section{Procedure}

The work in this Phase comprised:

The revised criteria were trialled using a large sample, of both geographic area and school type (EBD, SLD/MLD and Mainstream).

Pupils were assessed over a wide age range including infant, junior and secondary.

Schools were contacted about trials and materials were dispatched. Each school received instructions for administering the scales (instructions for teachers, evaluation forms, extended descriptions of the behaviours, teacher and a school details form). Teachers were instructed to complete the instrument by considering the behaviour of the specified pupil over the last three months and asked to try to complete all the forms for a particular class or group in one sitting. Further, they were asked to read through and understand the elaborations (given on a separate form) for each item on the checklist before attempting to complete the checklists. 
Initially, this section considers the properties of the items included within the behaviour rating scale and behaviour sub-scales, including a principal components factor analysis which considers how well the different items fit within each sub-scale (conduct, emotion, learning). Also, the extent to which items overlap is also considered. These together form the basis of further development of the scale to form a final version. Finally, some preliminary reliability and validity data is given, however, these would be initial indicators only due to the scale being in the development stages rather than trialled as a final version, further discussion of this will be continued in the discussion section.

Item analysis

With respect to the range of ratings, all points were used for some pupils for some items, including the lowest of 0 not at all , suggesting that even this lowest point should be included.

All means were around $3.5 \pm 0.4$ and had similar standard deviations and the same minimum and maximum of 0 and 5. Means would therefore correspond to the category between Fairly often and Often for a behaviour, and may be considered satisfactory.

A principal components factor analysis with Varimax Rotation was performed on the data and this showed three factors with a high Eigenvalue above 0.9. This generally confirmed the division of the scale into the three factors of conduct, learning and emotional behaviour, as shown below and accounted for $84 \%$ of the variance, (see Table 2). In addition, the correlations between the items were calculated.

[t/] Table 2 about here $[/ t]$

Conduct behaviour items. Items 1-7 all loaded most highly on the factor labelled conduct . However, items 3 and 4 correlated highly ( $r=0.91$ ) suggesting a degree of overlap. Further, item 7 correlated very uniformly with the other items in this group (r ranged from 0.80 to 0.84 ) suggesting a possible lack of differentiation.

Emotional behaviour items. Items 10, 11, 12 and 13 all loaded most highly on the emotional behaviour factor. However, item 8 loaded most highly on learning behaviour and 
items 9 and 14 on conduct behaviour. Items 13 and 14 correlated highly (r=0.87) to show a degree of duplication.

Learning behaviour items. All items in the group loaded most highly on the learning factor. A cluster of items $(15,16,17$ and 18$)$ all correlated highly with one another ( $r=0.88$ to $\mathrm{r}=0.92$ ), and again showed a high degree of overlap.

\section{Scale reliability}

Cronbach's alpha was calculated for each 7 item scale (conduct, emotion, learning) and each scale was shown to be reliable with alpha scores of $0.97,0.95$ and 0.97 respectively, well above the recommended value of 0.8 .

In addition, inter-rater reliability was assessed for conduct, emotion, learning and overall scores. These rating scores were taken from a sub-group of the total sample who had been assessed by more than one teacher. This sub-group comprised secondary aged pupils (years 7-11) only because primary aged pupils tended only to be taught by one class teacher. Clearly pupil behaviour will vary from classroom to classroom and subject to subject and will have an impact on the ratings given by particular teachers. To reduce the impact of this cross subject rating, ratings taken in Mathematics and English were selected as these subjects had the highest number of inter-rater completions and were regarded as similar in academic content as opposed to comparing mathematics and woodwork. These inter-rater reliability ratings were also further delineated by school type (Mainstream, EBD and MLD). The results of these inter-rater reliability correlations averaged across pairs of raters are presented in Table 3 below.

[t/] Table 3 about here $[/ t]$

It can be seen from the inter-rater reliability coefficients in table III that the inter-rater reliability for all of the scales when calculated across all of the school types was particularly high ranging from 0.64-0.78 even though the teachers were rating across different subject areas (Maths vs English). However, when the data was split into different school types (EBD, Mainstream, MLD) reliability was good for Mainstream and EBD however, ratings for MLD schools were poor with coefficients ranging from $0.03-0.45$. If the inter-rater reliability 
coefficients are calculated using Mainstream and EBD schools only improved ratings are obtained and are as follows conduct $=0.81$ (238), Learning $=0.69$ (235), Emotion $=0.71$ (236) and total rating $=0.79(230)$.

\section{Scale validity}

If the scale produces valid assessment of behaviour, then the distributions should be different for the different types of schools and different between genders. Clearly, the scales should be able to differentiate between overall scores for pupils within an EBD setting and those in a Mainstream setting. Additionally, it would be anticipated that females would be rated better behaviourally than males (Cooper et al., 1991; MacMillan et al., 1996; Cole et al., 1998;Loo \& Rapport, 1998). Means and 95\% confidence intervals are reported for EBD, Mainstream and MLD/SLD schools and for males and females in Table 4.

[t/] Table 4 about here $[/ \mathrm{t}]$

Table 4 illustrates that ratings for EBD schools for conduct, learning and emotion are lower than the ratings for MLD/SLD schools, which are in turn lower than mean ratings for Mainstream schools. Note that the 95\% confidence interval mean ranges do not overlap for the different school types, suggesting that the mean ratings for the different sub-scales do in fact decline from Mainstream to MLD/SLD to EBD settings.

In addition, females were rated as better behaved than males for each of the sub-scales (conduct, emotion, learning) with no overlap between the 95\% confidence intervals.

\section{Modifications and final version of the scales}

Item changes

The trial of the 21 items suggested that some items did not differ greatly from one another and that consequently a slightly shorter scale would be just as effective. Further, it is plausible to suggest that an abbreviated scale might be easier to use for its primary purpose of setting targets for school improvement. The shorter scale would have the advantage, particularly for Mainstream teachers, of being slightly quicker to complete, and also of 
identifying more specifically different areas. In addition, from the teacher evaluation, descriptors mentioned by teachers that would fit into a category were added. The following changes were made to the scale.

Conduct behaviour section. Items 3 'Only interrupts appropriately 'and 4 'Seeks attention appropriately' were merged because they correlated highly ( $\mathrm{r}=0.91)$ to be, 'Only interrupts and seeks attention appropriately’. Item 7, 'Observes school and teacher rules’, was criticized by teachers as being too general. It correlated uniformly at $r=0.80$ to 0.84 with the others in the section, and was removed.

Emotional behaviour section. Item 8, which correlated more highly with the learning items than the emotional behaviour ones, was removed. Item 9, 'Has empathy', which loaded with the learning items, was modified in the elaboration to emphasize the emotional aspect of its intended nature. Items 13, 'Is emotionally stable’, and 14, 'Shows good self control` which correlated highly ( $r=0.87$ ) were merged, to give, 'Is emotionally stable and shows self control'.

Learning Behaviour section. The cluster of items (15, 16, 17 and 18) which all correlated highly with one another ( $\mathrm{r}=0.88$ to $\mathrm{r}=0.92)$, and showed a high degree of overlap, were modified by merging items 15, 'Is attentive', and 16, 'Has an interest in school work', and items 17, 'Good learning organization', and 18, 'Shows perseverance in learning', and making changes to make them more distinctive. Thus the intention was to make (15 and 16), different in emphasis from (17 and 18). The revised versions were, 'Is attentive. Has an interest in school work', and 'Good learning organization'.

\section{Discussion}

Analysis of the final trial data shows that the items can be clustered under the three headings of conduct, emotion and learning as originally suggested. Additionally, all items showed satisfactory means and ranges demonstrating that the items were suitable for all age ranges and school types.

Where items correlate more than $r=0.87$ and they thus share more than $75 \%$ of the variance of an item there is concern that the item is not sufficiently different from others in what it assesses, and that there is a degree of redundancy. It is normally desirable for reasons 
of reliability to have more than one item assessing a particular behaviour, however, this conflicts with the aim of reducing the size of the instrument to allow teachers to complete them quickly and with the minimum of disruption. Further, it is plausible to suggest that an abbreviated scale might be easier to use for its primary purpose of setting targets for school improvement. Results indicate that Version 2 of the scale has good internal consistency and that inter-rater reliability is good. Therefore, it seems reasonable to reduce the items to a minimum for efficiency of completion. Generally the individual items assess different aspects of behaviour, but merging, modifying or deleting some items could attain some improvement.

The validity of Version 2 of the scale is supported by trends that show that the distributions are different for different types of schools with EBD institutions showing the lowest scores, followed by SLD/MLD and with Mainstream showing the highest scores. This suggests that the EBD teachers adopted normal population standards when rating pupils so that their behaviour relative to Mainstream pupils was reasonably accurately reflected.

Additionally, females were rated as better behaved than males in line with other studies (e.g., Cooper et al., 1991; MacMillan et al., 1996; Cole et al., 1998; Loo \& Rapport, 1998). As might be expected, there was least gender difference for emotional behaviour, and most for conduct behaviour. Additionally, scale reliability was shown to be high reflected by a high Cronbach s alpha score. However, such scale reliability and validity measures should be viewed cautiously as the scales were further modified as a result of the main trial findings, thus producing essentially a different scale (Version 3) that may be very different in terms of its reliability and validity.

Although inter-rater reliability (for Version 2) is good there is some inconsistency within SLD/MLD ratings with the learning and emotion sub-scales showing very low interrater coefficients. The reason for this may be because learning and emotion are particularly difficult behaviours to assess within the SLD/MLD environment, whereas conduct behaviour is much easier to judge, as reflected in the higher conduct coefficient of 0.45 compared to 0.06 and 0.03 for learning and emotion. In the light of these reliability findings it might be appropriate to suggest that the instrument is only suitable for Mainstream and EBD settings or for the instrument to be restricted to conduct items for SLD/MLD pupils.

Throughout the processes of design and consultation, the potential risk of misuse of the Scale was a recurrent theme. In the use of the scales in the assessment and identification of emotional and behavioural development, the importance of sensible and sound interpretation 
cannot be overstated. One aspect of this is that the whole context needs to be taken into account when interpreting the scale. In the past, education has tended to go through phases of being too narrow in its explanation of behaviour. It has progressively blamed the child, blamed the family, blamed the school, and blamed society. In reality all of these will have an effect and where possible, an approach that addresses all of them will be the most effective.

The project has produced a method of assessing behaviours, which has the useful potential to inform professional practice in the setting of targets for further emotional and behavioural development and for strategies in supporting school improvement (QCA, 2001). However, to be effective it needs to be used in a professional manner, with care taken to control for confirmatory bias or equating low scores with deficits in the child's capacity for development.

Scores reflect teacher perceptions and judgements, rather than pupil attributes per se. Their primary value is to promote critical and reflective debate within schools, focussing on the school environment, and ways in which practices can be developed in order to promote improved opportunities for pupils social and emotional growth. Repeated measures taken at regular intervals (e.g. yearly) will then allow schools to review the effectiveness of these practices, and become increasingly skilful in their endeavour to manage children s school experience in ways which maximize the emotional and behavioural development of all pupils.

It is recognized that the piloting of the instrument had a number of methodological weaknesses, namely, that piloting in the initial stages did not use a range of pupils but was constrained to Mainstream Year 9, and that piloting in phase 2 used opportunity sampling methods rather than a systematic or randomised sampling procedure. This is clearly an area for concern and future research should concentrate on establishing the instrument s reliability and validity through more stringent sampling conditions. In addition, it would be beneficial to extend testing to pupil completion to establish validity claims further.

The QCA publication (2001) presents an introductory summary of how initial approaches to school improvement might be adopted using the scale. Feedback from focus groups during the project and following the publication of the scale by the QCA revealed that several LEAs and many schools are using the assessment in creative ways as a means of developing a monitoring discourse of the kind described in the early part of this article. It is to be hoped that further development of the scale and more particularly its use in school 
effectiveness planning will secure emotional and social development as extrinsic aspects of curriculum management in the school setting.

\section{Conclusion}

The resulting instrument meets the original aims of being simple and quick to complete, which is very important if it is to be completed by teachers of relatively large teaching groups. However, it should be emphasized that the instrument is not intended to be used as a diagnostic tool, but to indicate potential process targets (see Kelly, 2001) for improvement using the cyclical target-setting and school improvement (DfEE, 1998). Further, it is regarded as a useful tool for providing a basis for a strategic discourse between staff for planning approaches to the emotional and behavioural development of students in school.

The final version of the scale with 15 items is shown in Appendix 3(a). It comprises three categories - Conduct, Emotional and Learning Behaviour-with five items in each. The rating is scored out of a total of 75 with 25 per category. Space has been added for a separate description of any other problems. In addition the elaborated descriptions of the individual items is also shown (Appendix 3(b)). 


\section{References}

Angelides, P. \& Ainscow, M. (2000) Making sense of the role of culture in school improvement, School Effectiveness and School Improvement: An International Journal of Research, Policy and Practice, 11(2), 145-163.

Argyris, C. \& Schon, D. (1978) Organizational learning: a theory of action perspective (New York, Addison-Wesley).

Bate, C. \& Moss, J. (1997) Towards a behaviour curriculum, Educational Psychology in Practice, 13, 176-180.

Bennathan, M. \& Boxall, M. (1998) The Boxall Profile: a guide to effective intervention in the education of pupils with emotional and behavioural difficulties, Handbook for Teachers (AWCEBD, Maidstone, England).

Birmingham LEA. (1998) Frameworks (Birmingham, Birmingham LEA).

Burrell, G. \& Morgan, G. (1979) Sociological paradigms and organizational analysis (London, Heinemann Educational Books).

Cohen, L., Manion, L. \& Morrison, K. (2001) Research methods in education (5th edn) (London, Routledge-Falmer).

Cole, T., Visser, J., \& Upton, G. (1998) Effective schooling for pupils with emotional and behavioural difficulties (London, David Fulton Publishers).

Cooper, P., Upton, G., \& Smith, C. (1991) Ethnic minority and gender distribution among staff and pupils with emotional and behavioural difficulties in England and Wales, British Journal of Sociology of Education, 12, 77-94.

Department for Education (DfE) (1993) Code of practice: on the identification and assessment of special educational needs (London, DfE).

Department for Education and Employment (DfEE) (1997) Excellence for all children: meeting special educational needs (London, DfEE).

Department for Education and Employment (DfEE) (1998) Supporting the target-setting process: guidance for effective target-setting for pupils with special educational needs (DfEE Publications, Nottingham).

Greenhalgh, P. (1994) Emotional growth and learning (London, Routledge).

Guba, E. \& Lincoln, Y. (1989) Fourth generation evaluation (London, Sage).

Kline, P. (1993) The handbook of psychological testing (London, Routledge).

Loo, S. K. \& Rapport, M. D. (1998) Ethnic variations in children s problem behaviors: a cross-sectional development study of Hawaii school children, Journal of Child Psychology and Psychiatry, 39, 567-575.

Macmillan, D. L., Gresham, F. G., Lopez, M. F. \& Bocian, K. M. (1996) Comparison of students nominated for prereferral interventions by ethnicity and gender, Journal of Special Education, 30, 133-151.

Margerison, A. \& Rayner, S. (1999) Troubling targets and school needs: Assessing behaviour in the classroom, Support for Learning, 14(2), 87-92. 
Qualifications and Curriculum Authority (QCA) (2001) Supporting school improvement: emotional and behavioural development (London, Qualifications and Curriculum Authority).

Riding, R. J. \& Al-Hajji, J. (2001) The effect of home background, gender, cognitive style and self-perception on school performance, in: R. J. Riding \& S. G. Rayner (Eds) Selfperception: International perspectives on individual differences, Volume 2 (Stamford CT, Ablex).

Robson, C. (2002) Real world research (2nd edn (Oxford, Blackwell).

Senge, P. (1990) The fifth discipline: the art and practice of the learning organization (New York, Doubleday).

Senge, P. (1994) The fifth discipline fieldbook: strategies and tools for building a learning organization (London, Nicholas Brearley).

Senge, P. (1999) The dance of change: the challenges of sustaining momentum in learning organizations (London, Nicholas Brearley).

Sherman, R. \& Webb, R. (Eds) (1998) Qualitative research in education: focus and methods (London, Falmer Press).

Walker, H. M. \& Mcconnell, S. R. (1995) Walker-McConnell Scale of social competence and school adjustment (San Diego, Singular Publishing Group). 


\section{Appendix 1. Version 1 of the rating scale as used in preliminary trial}

\begin{tabular}{|c|c|c|}
\hline Undesirable or Negative Behaviour & & Desirable or Positive Behaviour \\
\hline $\begin{array}{l}\text { 1. Uncooperative and disobedient. } \\
\text { E.g. Talks back to the teacher, responds negatively to } \\
\text { direction. }\end{array}$ & 1234567 & $\begin{array}{l}\text { Is co-operative and compliant. } \\
\text { Responds positively to direction. }\end{array}$ \\
\hline $\begin{array}{l}\text { 2. Lacks respect for teachers. } \\
\text { E.g. Interrupting, quarrelling, deliberately annoying, } \\
\text { answering teachers rudely. }\end{array}$ & 1234567 & $\begin{array}{l}\text { Respects teachers. } \\
\text { Listens and answers teachers politely. }\end{array}$ \\
\hline $\begin{array}{l}\text { 3. Has poor respect for other pupils. } \\
\text { E.g. Aims verbal aggression at other pupils, teases, calls } \\
\text { names, uses psychological intimidation, swears. }\end{array}$ & 1234567 & $\begin{array}{l}\text { Has respect for other pupils. } \\
\text { Interacts with other pupils politely and thoughtfully. }\end{array}$ \\
\hline $\begin{array}{l}\text { 4. Is passive and withdrawn. } \\
\text { E.g. unresponsive to stimulation, often staring into space, } \\
\text { day-dreaming. }\end{array}$ & 1234567 & $\begin{array}{l}\text { Is active and forthcoming. } \\
\text { Responsive to stimulation. }\end{array}$ \\
\hline $\begin{array}{l}\text { 5. Is disruptive to others. } \\
\text { E.g. Passes notes in class, throws things, shouts out, fidgets, } \\
\text { hums, taps, talks when others are talking. }\end{array}$ & 1234567 & $\begin{array}{l}\text { Does not disrupt. } \\
\text { Does not distract or interfere with others. }\end{array}$ \\
\hline $\begin{array}{l}\text { 6. Shows attention seeking behaviour. } \\
\text { E.g. Behaves like a clown, calls out in class, has need for } \\
\text { adult contact, behaves in a silly manner. }\end{array}$ & 1234567 & $\begin{array}{l}\text { Does not seek unwarranted attention. } \\
\text { Pupil behaves in ways warranted by the current } \\
\text { classroom activity. }\end{array}$ \\
\hline $\begin{array}{l}\text { 7. Displays physical aggression towards pupils or teachers. } \\
\text { E.g. Picks on others, is cruel, spiteful, gets into fights, strikes } \\
\text { out in temper. }\end{array}$ & 1234567 & $\begin{array}{l}\text { Is not physically aggressive. } \\
\text { Avoids fights, is pleasant to other pupils. }\end{array}$ \\
\hline $\begin{array}{l}\text { 8. Has poor respect for property. } \\
\text { E.g. Damages or destroys property. }\end{array}$ & 1234567 & $\begin{array}{l}\text { Respects property. } \\
\text { Values and looks after property. }\end{array}$ \\
\hline $\begin{array}{l}\text { 9. Is easily distracted. } \\
\text { E.g. Has difficulty keeping on task, trouble paying attention, } \\
\text { fails to complete work, difficulty concentrating. }\end{array}$ & 1234567 & $\begin{array}{l}\text { Is attentive. } \\
\text { Not easily distracted, completes work, keeps on task } \\
\text { and concentrates. }\end{array}$ \\
\hline $\begin{array}{l}\text { 10. Lacks interest in school work. } \\
\text { E.g. Gives up easily, poor motivation, little effort. }\end{array}$ & 1234567 & $\begin{array}{l}\text { Has an interest in school work. } \\
\text { Perseveres with tasks, good motivation, shows } \\
\text { interest. }\end{array}$ \\
\hline $\begin{array}{l}\text { 11. Poor learning approach. } \\
\text { E.g. Is disorganized, messy, slow, fussy, gets overly occupied } \\
\text { with one activity, can t make choices. }\end{array}$ & 1234567 & $\begin{array}{l}\text { Good learning approaches. } \\
\text { Works neatly, at a reasonable pace, knows when to } \\
\text { move onto next activity or stage, can make choices. }\end{array}$ \\
\hline $\begin{array}{l}\text { 12. Shows inappropriate learning behaviour. } \\
\text { E.g. Is lazy, copies, has negative approach to school work. }\end{array}$ & 1234567 & $\begin{array}{l}\text { Shows appropriate learning behaviour } \\
\text { Is conscientious, independent, has a positive } \\
\text { approach to school work. }\end{array}$ \\
\hline $\begin{array}{l}\text { 13. Deliberately breaks school or teacher rules. } \\
\text { E.g. Fails to give in homework, skips classes, leaves seat } \\
\text { without permission, tells lies. }\end{array}$ & 1234567 & $\begin{array}{l}\text { Observes school and teacher rules. } \\
\text { Gives in homework, attends classes, does not leave } \\
\text { seat without permission. }\end{array}$ \\
\hline $\begin{array}{l}\text { 14. Has communication problems. } \\
\text { E.g. Speech incoherent, Limited non-verbal support of } \\
\text { speech, answers without thinking. Interrupts inappropriately } \\
\text { during conversation. }\end{array}$ & 1234567 & $\begin{array}{l}\text { Is an effective communicator. } \\
\text { Has no speech problems, thinks before answering. }\end{array}$ \\
\hline $\begin{array}{l}\text { 15. Lacks social skills. } \\
\text { E.g. Has trouble waiting turn, pushes ahead in lines, not well } \\
\text { liked, intolerant of others, refuses to share, avoids looking } \\
\text { others in eye. }\end{array}$ & 1234567 & $\begin{array}{l}\text { Has got good social skills. } \\
\text { Can wait turn, is well liked, is tolerant of others, } \\
\text { shares with others, is sociable. }\end{array}$ \\
\hline $\begin{array}{l}\text { 16. Makes excessive demands. } \\
\text { E.g. Constantly seeks help, persists and nags. }\end{array}$ & 1234567 & $\begin{array}{l}\text { Does not make excessive demands. } \\
\text { Seeks help only when appropriate. }\end{array}$ \\
\hline $\begin{array}{l}\text { 17. Is solitary. } \\
\text { E.g. Keeps to ones self, loner, isolated. }\end{array}$ & 1234567 & $\begin{array}{l}\text { Is sociable. } \\
\text { Interacts normally with others. }\end{array}$ \\
\hline $\begin{array}{l}\text { 18. Is unhappy. } \\
\text { E.g. Sad, inability to have fun, often tearful, cries easily, } \\
\text { whining, depressed, serious. }\end{array}$ & 1234567 & $\begin{array}{l}\text { Is happy. } \\
\text { Has fun when appropriate, smiles, laughs, is } \\
\text { cheerful. }\end{array}$ \\
\hline $\begin{array}{l}\text { 19. Lacks confidence. } \\
\text { E.g. Low self-esteem, fears failure, self conscious, shy, } \\
\text { worries about things, is afraid of new things, anxious, un- } \\
\text { relaxed, cautious. }\end{array}$ & 1234567 & $\begin{array}{l}\text { Is confident. } \\
\text { High self-esteem, relaxed. }\end{array}$ \\
\hline $\begin{array}{l}\text { 20. Displays inappropriate emotional reactions. } \\
\text { E.g. Mood swings, hides emotions, is unresponsive to } \\
\text { affection, shows little affection, lacks emotional resilience. }\end{array}$ & 1234567 & $\begin{array}{l}\text { Is emotionally stable. } \\
\text { Shows appropriate reactions in emotional situations, } \\
\text { responsive to affection, shows appropriate affection. }\end{array}$ \\
\hline $\begin{array}{l}\text { 21. Is irritable. } \\
\text { E.g. Easily frustrated, touchy, easily flustered, loses temper. }\end{array}$ & 1234567 & $\begin{array}{l}\text { Is calm and controlled. } \\
\text { Patient, not easily flustered. }\end{array}$ \\
\hline
\end{tabular}




\section{Appendix 2. Emotional and Behavioural Scale (Version 2)}

EMOTIONAL AND BEHAVIOURAL DEVELOPMENT SCALE

\begin{tabular}{|c|c|c|c|c|c|c|}
\hline Desirable Behaviour & Not at all & Rarely & Sometimes & Fairly Often & Often & Always \\
\hline CONDUCT BEHAVIOUR & \multicolumn{5}{|l|}{$\begin{array}{l}\text { Very } \\
\text { Poor }\end{array}$} & $\begin{array}{l}\text { Very } \\
\text { Good }\end{array}$ \\
\hline \multicolumn{7}{|l|}{$\begin{array}{l}\text { 1. Behaves respectfully towards teachers. } \\
\text { E.g. Respects teachers and answers teachers politely, does not interrupt } \\
\text { or deliberately annoy, does not show verbal aggression. }\end{array}$} \\
\hline \multicolumn{7}{|l|}{$\begin{array}{l}\text { 2. Shows respect to other pupils. } \\
\text { E.g. Interacts with other pupils politely and thoughtfully, does not tease, } \\
\text { call names, swear, use psychological intimidation. }\end{array}$} \\
\hline \multicolumn{7}{|l|}{$\begin{array}{l}\text { 3. Only interrupts appropriately. } \\
\text { E.g. Does not disrupt unnecessarily, does not distract or interfere with } \\
\text { others, does not pass notes, fidget, hum, talk when others are talking. }\end{array}$} \\
\hline \multicolumn{7}{|l|}{$\begin{array}{l}\text { 4. Seeks attention appropriately. } \\
\text { E.g. Does not seek unwarranted attention, pupil behaves in ways } \\
\text { warranted by the current classroom activity, does not behave in a silly } \\
\text { manner or call out in class. }\end{array}$} \\
\hline \multicolumn{7}{|l|}{$\begin{array}{l}\text { 5. Is physically peaceable. } \\
\text { E.g. Is not physically aggressive, avoids fights, is pleasant to other } \\
\text { pupils, is not cruel or spiteful, does not strike out in temper. }\end{array}$} \\
\hline \multicolumn{7}{|l|}{$\begin{array}{l}\text { 6. Respects property. } \\
\text { E.g. Values and looks after property, does not damage or destroy } \\
\text { property does not steal. }\end{array}$} \\
\hline \multicolumn{7}{|l|}{$\begin{array}{l}\text { 7. Observes school and teacher rules. } \\
\text { E.g. Attends classes, does not leave seat without permission, does not } \\
\text { tell lies. }\end{array}$} \\
\hline \multicolumn{7}{|l|}{ EMOTIONAL BEHAVIOUR } \\
\hline \multicolumn{7}{|l|}{$\begin{array}{l}\text { 8. Is active and forthcoming. } \\
\text { E.g. Responsive to surroundings, does not stare into space, day-dream } \\
\text { excessively. . }\end{array}$} \\
\hline \multicolumn{7}{|l|}{$\begin{array}{l}\text { 9. Has empathy. } \\
\text { E.g. Is tolerant of others, shows understanding and sympathy, is } \\
\text { considerate. }\end{array}$} \\
\hline \multicolumn{7}{|l|}{$\begin{array}{l}\text { 10. Is socially aware. } \\
\text { E.g. Interacts appropriately with others, is not a loner or isolated. }\end{array}$} \\
\hline \multicolumn{7}{|l|}{$\begin{array}{l}\text { 11. Is happy. } \\
\text { E.g. Has fun when appropriate, smiles, laughs, is cheerful, is not tearful, } \\
\text { depressed, whining. }\end{array}$} \\
\hline \multicolumn{7}{|l|}{$\begin{array}{l}\text { 12. Is confident. } \\
\text { E.g. Is not anxious, high self-esteem, relaxed, does not fear failure, is } \\
\text { not shy, afraid of new things, is robust. }\end{array}$} \\
\hline \multicolumn{7}{|l|}{$\begin{array}{l}\text { 13. Is emotionally stable. } \\
\text { E.g. Moods remain relatively stable, does not have frequent mood } \\
\text { swings. }\end{array}$} \\
\hline \multicolumn{7}{|l|}{$\begin{array}{l}\text { 14. Shows good self control. } \\
\text { E.g. Patient, not easily flustered, not touchy. }\end{array}$} \\
\hline \multicolumn{7}{|l|}{ LEARNING BEHAVIOUR } \\
\hline \multicolumn{7}{|l|}{$\begin{array}{l}\text { 15. Is attentive. } \\
\text { E.g. Not easily distracted, completes work, keeps on task and } \\
\text { concentrates. }\end{array}$} \\
\hline \multicolumn{7}{|l|}{$\begin{array}{l}\text { 16. Has an interest in school work. } \\
\text { E.g. Good motivation, shows interest, enjoys school work. }\end{array}$} \\
\hline \multicolumn{7}{|l|}{$\begin{array}{l}\text { 17. Good learning organization. } \\
\text { E.g. Works systematically, at a reasonable pace, knows when to move } \\
\text { onto next activity or stage, can make choices, is organized. }\end{array}$} \\
\hline \multicolumn{7}{|l|}{$\begin{array}{l}\text { 18. Shows perseverance in learning. } \\
\text { E.g. Is conscientious, independent, has a positive approach to school } \\
\text { work, perseveres with tasks. }\end{array}$} \\
\hline \multicolumn{7}{|l|}{$\begin{array}{l}\text { 19. Is an effective communicator. } \\
\text { E.g. Speech is coherent, thinks before answering. }\end{array}$} \\
\hline \multirow{2}{*}{\multicolumn{7}{|c|}{$\begin{array}{l}\text { 20. Works efficiently in a group. } \\
\text { E.g. Takes part in discussions, contributes readily to group tasks, listens } \\
\text { well in groups, works collaboratively. } \\
\text { 21. Seeks help where necessary. } \\
\text { E.g. Does not make excessive demands on the teacher }\end{array}$}} \\
\hline & & & & & & \\
\hline & \begin{tabular}{|l|l} 
Not at all \\
\end{tabular} & $\begin{array}{l}\text { Rarely } \\
\end{array}$ & Sometimes & Fairly Often & Often & Always \\
\hline
\end{tabular}




\section{Appendix 3(a). Emotional and Behavioural Scale-Final Version}

\section{EMOTIONAL AND BEHAVIOURAL DEVELOPMENT SCALE}

Name:

Age:

Date:

\begin{tabular}{|c|c|c|c|c|c|c|}
\hline \multirow[t]{2}{*}{ Desirable Behaviour } & Not at all & Rarely & Sometimes & $\begin{array}{c}\text { Fairly } \\
\text { Often } \\
\end{array}$ & Often & Always \\
\hline & \multicolumn{5}{|l|}{$\begin{array}{c}\text { Very Poor } \\
0\end{array}$} & $\begin{array}{l}\text { Very Good } \\
5\end{array}$ \\
\hline \multicolumn{7}{|l|}{ CONDUCT BEHAVIOUR } \\
\hline \multicolumn{7}{|l|}{$\begin{array}{l}\text { 1. Behaves respectfully towards teachers. } \\
\text { E.g. Respects teachers and answers teachers politely, does not } \\
\text { interrupt or deliberately annoy, does not show verbal } \\
\text { aggression. }\end{array}$} \\
\hline \multicolumn{7}{|l|}{$\begin{array}{l}\text { 2. Shows respect to other pupils. } \\
\text { E.g. Interacts with other pupils politely and thoughtfully, does } \\
\text { not tease, call names, swear, use psychological intimidation. }\end{array}$} \\
\hline \multicolumn{7}{|l|}{$\begin{array}{l}\text { 3. Only interrupts and seeks attention appropriately. } \\
\text { E.g. Pupil behaves in ways warranted by the classroom activity. } \\
\text { Does not disrupt unnecessarily, or distract or interfere with } \\
\text { others, does not pass notes, talk when others are talking. Does } \\
\text { not seek warranted attention, }\end{array}$} \\
\hline \multicolumn{7}{|l|}{$\begin{array}{l}\text { 4. Is physically peaceable. } \\
\text { E.g. Is not physically aggressive, avoids fights, is pleasant to } \\
\text { other pupils, is not cruel or spiteful, does not strike out in } \\
\text { temper. }\end{array}$} \\
\hline \multicolumn{7}{|l|}{$\begin{array}{l}\text { 5. Respects property. } \\
\text { E.g. Values and looks after property, does not damage or } \\
\text { destroy property, and does not steal. }\end{array}$} \\
\hline \multicolumn{7}{|l|}{ EMOTIONAL BEHAVIOUR } \\
\hline \multicolumn{7}{|l|}{$\begin{array}{l}\text { 6. Has empathy. } \\
\text { E.g. Is tolerant of others, shows understanding and sympathy, } \\
\text { is considerate. }\end{array}$} \\
\hline \multicolumn{7}{|l|}{$\begin{array}{l}\text { 7. Is socially aware. } \\
\text { E.g. Interacts appropriately with others, is not a loner or } \\
\text { isolated; reads social situations well. }\end{array}$} \\
\hline \multicolumn{7}{|l|}{$\begin{array}{l}\text { 8. Is happy. } \\
\text { E.g. Has fun when appropriate, smiles, laughs, is cheerful, is } \\
\text { not tearful or depressed. }\end{array}$} \\
\hline \multicolumn{7}{|l|}{$\begin{array}{l}\text { 9. Is confident. } \\
\text { E.g. Is not anxious, high self-esteem, relaxed, does not fear } \\
\text { failure, is not shy, afraid of new things, is robust. }\end{array}$} \\
\hline \multicolumn{7}{|l|}{$\begin{array}{l}\text { 10. Is emotionally stable and shows self control. } \\
\text { E.g. Moods remain relatively stable, does not have frequent } \\
\text { mood swings. Patient, not easily flustered, not touchy. }\end{array}$} \\
\hline \multicolumn{7}{|l|}{ LEARNING BEHAVIOUR } \\
\hline \multicolumn{7}{|l|}{$\begin{array}{l}\text { 11. Is attentive. Has an interest in school work. } \\
\text { E.g. Not easily distracted, completes work, keeps on task and } \\
\text { concentrates. Good motivation, shows interest, enjoys school } \\
\text { work }\end{array}$} \\
\hline \multicolumn{7}{|l|}{$\begin{array}{l}\text { 12. Good learning organization. } \\
\text { E.g. Works systematically, at a reasonable pace, knows when to } \\
\text { move onto next activity or stage, can make choices, is } \\
\text { organized. }\end{array}$} \\
\hline \multicolumn{7}{|l|}{$\begin{array}{l}\text { 13. Is an effective communicator. } \\
\text { E.g. Speech is coherent, thinks before answering. }\end{array}$} \\
\hline \multicolumn{7}{|l|}{$\begin{array}{l}\text { 14. Works efficiently in a group. } \\
\text { E.g. Takes part in discussions, contributes readily to group } \\
\text { tasks, listens well in groups, works collaboratively. }\end{array}$} \\
\hline $\begin{array}{l}\text { 15. Seeks help where necessary. } \\
\text { E.g. Seeks teacher help when needed. }\end{array}$ & & & & & & \\
\hline
\end{tabular}

\section{Additional Comments:}


AIE 11/3, Paper 3, p. 29

\section{Appendix 3(b). Emotional and Behavioural Scale Description of Items (Final Version )}

To clarify the positive descriptors examples of negative behaviours are included in italics for each item.

\section{Behaves respectfully towards teachers.}

\section{CONDUCT BEHAVIOUR}

A pupil who respects the teacher will be co-operative and compliant, responding positively to instruction. The pupil does not talk back to the teacher or aim verbal aggression at the teacher. The pupil interacts politely with the teacher. The pupil will not be quarrelsome or deliberately try to annoy the teacher and will not interrupt or answer the teacher rudely.

A pupil may respond negatively to instruction, talk back to teacher, be uncooperative with teacher, impertinent to teacher, aim verbal violence at teacher, swear in teachers presence, answer teacher rudely, be quarrelsome with teacher, deliberately annoy teacher, interrupt teacher, think it s funny to make teacher angry.

\section{Shows respect to other pupils.}

A pupil who has respect for other pupils will use appropriate language, for example, not swearing or calling them names. The pupil will treat other pupils as equals and not dominate with the use of intimidation or abuse. They will also respect the views or rights of other pupils and avoid bullying or intimidation.

A pupil may aim verbal violence at other pupils, use psychological intimidation, show social aggression, be scornful with other students, call other pupils names, tease, try to dominate, use unethical behaviour e.g. inappropriate sexual behaviour, blame others, push ahead in lines.

\section{Only interrupts and seeks attention appropriately.}

The pupil does not seek to attract inappropriate attention to him/herself in the classroom. The pupil acts in a manner appropriate to the classroom situation and does not play the fool, try to make the class laugh, shout out smart remarks or show off in the classroom. The pupil does not display attention-seeking behaviour. The pupil does not unnecessarily disrupt or interrupt other pupils who are working. Verbal disruptions such as unauthorised talking to other pupils are kept to a minimum. S/he does not disrupt other pupils using physical disruption such as nudging or poking.

A pupil may hum, fidget, disturb or disrupt others, display unauthorised talking to other pupils, attention seek, make the rest of the class laugh, pass notes in class, be verbally disruptive, throw things about during lessons, often talk when someone else is talking, climb on things, run around classroom, tap foot or pencil, call out in class, eats sucks or drink inedible substances, behave like a clown, be loud, get into everything, hyperactive, act smart, show concern for immediate rewards, need excessive adult contact, be excitable, do dangerous things without thinking, tell imaginary things, shout in class.

\section{Is physically peaceable.}

The pupil does not show physical aggression towards adults or other pupils. S/he does not physically pick on others, is not cruel or spiteful to others and avoids getting into fights with others. The pupil does not strike out in anger, have temper tantrums or aggressive outbursts.

A pupil may fight, aim physical violence at other students, often lose temper, yell and throw things, bully, aim physical violence at teachers, force other students to do things against their will, be deliberately cruel, pick on others, try to get even, be spiteful.

\section{Respects property.}

The pupil respects the property of others. This may be seen by the pupil taking good care of property. The pupil does not take part in acts of wilful damage or destruction. The pupil does not steal from others.

A pupil may have poor respect for property, destroy own things, destroy others things, , damage school property, steals things. 


\section{Has empathy.}

\section{EMOTIONAL BEHAVIOUR}

The pupil is tolerant and considerate towards others.. The pupil understands how others are feeling and tries to act appropriately to the situation, e.g. the pupil may try to comfort someone who is upset or hurt. The pupil displays situationally appropriate emotions and is not emotionally detached, and does not laugh at someone who is upset or injured.

A pupil may lack the ability to take on the role of others, be intolerant of others, be emotionally detached, be selfish, have no awareness of others feelings.

\section{Is socially aware.}

The pupil who is socially aware will be conscious of, and understand, the social interactions happening around them. S/he will interact appropriately with other people both verbally and nonverbally. S/he will not be socially isolated and not spend long periods of time sitting or standing alone. The pupil will have friends among his/her peers, and not be a loner. Day-dreaming and staring into space will be infrequent. The pupil will be actively involved in activities within the classroom, and will not seem aloof, inactive, passive or withdrawn.

A pupil may day-dream, stare into space, be inactive, be passive, be aloof, be out of touch with reality, be withdrawn and unresponsive to stimulation, show non participation in class activities, be unaccepted, be not well liked, lack accurate perceptions of others, say feel they do not have any friends, stare blankly, be listless, show bizarre behaviours, lack self awareness.

\section{Is happy.}

The pupil will appear happy by smiling and laughing when appropriate. S/he should be able to have fun. The pupil will generally be cheerful and not tearful and emotionally upset. The pupil will not be discontented, sulky, morose or miserable.

A pupil may be depressed, discontented, unhappy, distressed, talk about not wanting to live, be prone to emotional upset, be unable to have fun, be tearful on arrival, cry easily, be sullen or sulky, be serious or sad, be self harming, be pessimistic

\section{Is confident.}

The pupil is not anxious and is confident in most situations, albeit not showing bravado, recklessness or unrealistic expectations of her/his competence. S/he is not afraid of new things and does not fear failure when taking on new tasks. The pupil is not self conscious or shy in most situations and does not feel inferior to other pupils. The pupil is willing to read out loud in class and put their hand up to answer or ask appropriate questions. S/he is typically forthcoming in group/class discussions.

A pupil may act extremely frightened to the point of crying, be anxious, unrelaxed, fearful, upset by new people or situations, reticent, suck thumb or bite nails, lack confidence, fear failure, have feelings of inferiority, worry about things that can $t$ be changed, be negativistic, afraid of new things, feel unable to succeed, lack self-esteem, be self conscious, be overly submissive, be cautious, be shy, not take initiative.

\section{Is emotionally stable and shows good self control.}

The pupil s moods remain relatively stable and do not frequently swing from positive to negative. If upset s/he soon returns to a stable frame of mind, and shows good emotional resilience and is not moody. The pupil will show good self control, with an ability to manage his/her feelings and actions to suit the situation. The pupil is not easily frustrated or flustered and does not show signs of being touchy or uneasy. S/he is able to delay gratification when required, and can wait for rewards or pleasurable items for prolonged periods of time

A pupil may be touchy, display inappropriate emotional reactions, have difficulty expressing needs and feelings, have frequent or strong mood changes, be irritable, tough minded, stay disappointed for a long time if favourite activity is cancelled, inability to delay gratification, easily flustered, sensitive, poor respect for self, over react to normal situations, not accept punishment or praise, instigate poor situations, cannot accept responsibility. 


\section{LEARNING BEHAVIOUR}

\section{Is attentive and has an interest in school work.}

A pupil who is attentive listens to the teacher and is not easily distracted from the task in hand. S/he should not find it difficult to work when others around him/her are talking at a reasonable level. The pupil shows an interest in most school work. S/he gets started on tasks without delay and has the motivation to carry them through. The pupil generally gets enjoyment from school tasks and consequently completes them without complaint.

A pupil may show verbal off task behaviour, lack interest, not finish work, not listen or hear, have to be reminded again and again, have trouble paying attention, find it hard to sit still, not concentrate on tasks, have a short attention span, be easily distracted, fail to maintain interest in work, give up easily, have a negative approach to school work in general, be lazy, respond negatively to school, be frequently absent or late in arrival at lessons, be late arrival at school, not have ambition, not be keen to achieve.

\section{Good learning organization.}

The pupil competently copes with individual learning situations. The pupil produces tidy work, at a reasonable pace. The pupil seems to have a good grasp of how to organize learning tasks so that they can be successfully completed. This item deals with organization deficits which significantly hamper the learning of the individual rather than motivational aspects.

A pupil may be forgetful, copy, have trouble organizing school work, rush into things without thinking, appear confused about learning tasks, be slow/not accurate, worry about things that can $t$ be changed, get occupied overly with one activity, get easily frustrated, have difficulty in making choices, be fussy, school work messy, does not meet targets/deadlines, complain of not being able to cope with schoolwork, not prepared for lessons.

\section{Is an effective communicator.}

The pupil will show good communication skills. S/he should be able to communicate effectively with adults and peers. S/he will be coherent, know when it is appropriate to speak, be able to alter voice pitch and tone appropriately and use non-verbal signals effectively, i.e. eye contact, stance, distance, etc. The pupil should be able to organize communication in both individual and group situations. This item refers to using or ignoring social communication and not medical problems, e.g. stuttering.

A pupil may answer before a question is finished, not attempt to furnish information when requested, answer without stopping to think, not use language to communicate, have repetitive speech, have incoherent speech, avoid looking others in the eye, have difficulty communicating, have a speech difficulty, have Limited non-verbal support of speech, have difficulty planning behaviour and feedback and responding to feedback, have limited non-verbal communication of attitudes and emotions, talk constantly.

\section{Works efficiently in a group.}

The pupil works well in a group situation. S/he works collaboratively with others and is an effective communicator in group discussions. The pupil listens to what others have to say and consequently adds positively to group discussions. The pupil is willing to take on responsibilities within a group context.

A pupil may refuse to share with another student, have trouble waiting turn, refuse interactive games or tasks, not willingly work collaboratively.

\section{Seeks help where necessary.}

The pupil seeks attention from the teacher when appropriate. The pupil works independently until s/he comes upon a problem which cannot be solved without teacher help.

A pupil may be unable to work independently, constantly seek help, have excessive demands, persist and nag, not seek information appropriately or ask relevant questions. 